\title{
Effectiveness of Retirement Adjustment Scale Among Retired Teachers from Southwestern Nigeria
}

\author{
Emily Oluseyi Adeyemo, ${ }^{1, \text { * }}$, Onijuni Olufemi Olatomide ${ }^{2}$ \\ Department of Educational Foundations and Counselling, Faculty of Education, Obafemi Awolowo University, Ile-Ife, Nigeria
}

Email address:

seyiadeyemo2007@yahoo.com (E. O. Adeyemo)

${ }^{*}$ Corresponding author

\section{To cite this article:}

Emily Oluseyi Adeyemo, Onijuni Olufemi Olatomide. Effectiveness of Retirement Adjustment Scale Among Retired Teachers from Southwestern Nigeria. Education Journal. Vol. 10, No. 4, 2021, pp. 160-165. doi: 10.11648/j.edu.20211004.17

Received: May 27, 2021; Accepted: June 10, 2021; Published: August 18, 2021

\begin{abstract}
Retirement is seen as partial or complete disengagement from work activities with which individuals have been identified, due to personal or organizational factors, whether or not retirement benefits would accompany $i t$. Being a significant phase of transition into human life, the phase offers unique opportunities for researchers to investigate adaptation and coping over the period, because it is reputed for considerable daily life changes that impacts retirees' psychological health. The study explored the practical workability of measuring retirement adjustment intended for Retirement Adjustment Scale (RAS) among teachers who retired from primary and secondary schools in Ekiti and Osun States of the Southwestern Nigeria. It also investigated the effectiveness or otherwise of RAS among the respondents based on their demographics such as gender, educational attainment and institution of service before transition into retirement. The research design adopted was survey. The population comprised all retired teachers from primary and secondary schools in Ekiti and Osun States of Southwestern Nigeria. The sample size $(n=650)$ was selected through a multi-stage sampling, 650 copies of questionnaire were administered. The results revealed that the level of effectiveness of RAS in measuring the retirement adjustment of retiree was moderately high. There was no statistically significant effect on retirees' sex $\left(\chi^{2}=1.376, p>0.05\right)$ and type of family $\left(\chi^{2}=\right.$ $2.046, p>0.05)$ whereas there was a significant effect on retirees' educational attainment $\left(\chi^{2}=22.823, p<0.05\right)$ and institution of service before retirement $\left(\chi^{2}=37.974, p<0.05\right)$. There was no significant difference in the effectiveness of RAS in measuring the retirement adjustment of the retired teachers on the basis of $\operatorname{sex}(t=1.593, p>0.05)$. It could be concluded that RAS is effective in measuring the retirement adjustment of teacher-retirees from both primary and secondary schools on the most important variables of sex while variation may exist in the matter of their educational attainment and institution of service prior to retirement.
\end{abstract}

Keywords: Retirement Adjustment, Scale, Effectiveness, Retiree

\section{Introduction}

Researchers across climes have variously defined retirement. To [1], retirement connotes a range of activities, a process, or a state of affair, while it is also described as the final phase of events in an individual's occupational life which shows the period following a career employment in which occupational tasks are withdrawn [2]. More recently, Adeyemo expressed retirement as partial or complete disengagement from work activities with which individuals have been identified [3], due to personal or organizational factors, whether or not retirement benefits would accompany it. Administratively, retirement could be voluntary (also called self-retirement), mandatory (otherwise called statutory retirement), or compulsory (or forced) [3]. The type of retirement, notwithstanding, retirement is a transition from one phase of life to another $[4,5]$. Retirement is thus a unique stage in individual's total life and career trajectory.

Being a significant phase of transition in human life, transition into the phase offers unique opportunities for researchers to investigate adaptation and coping over the period, because it is reputed for considerable daily life changes that impacts retirees' general psychological health 
[6]. Relatedly, the problems faced by retirees globally (including Nigeria) have induced numerous psychological and emotional feelings linked to erosion of confidence, insecurity, and unpreparedness [7]. Specifically, while workers in Nigeria would engage in many malpractices such as age falsification and alteration of records of service to defer going into retirement, being perceived as a dreadful phenomenon [8], Nigerian retirees experience post-retirement difficulties such as delay in payment of retirement entitlements, absence of retirement home, absence of social welfare system, large number of dependents and unemployed children, among others [9-11]. This underscores the need to explore how retirees are adjusting to retirement phenomena. Consequently, [3] validated a Retirement Adjustment Scale (RAS) for secondary school teacher- retirees in Osun State of Nigeria.

The RAS had 21 items, most of which had a high mean of 3.00 except for one of the items that had 1.70, which generally indicated a positive disposition, homogeneity and items appropriateness. The principal Component analysis released six components $\mathrm{F} 1$ to $\mathrm{F} 6$, jointly attributing to $60.11 \%$ of the total variance, and the overall reliability coefficient Cronbach $(\alpha=0.782)$ statistically significant showing a high degree of internal consistency reliability for group analysis. Almost all the items but three had a Communality (C) greater than 0.5 , indicating a satisfactory quality of the six-factor components model of RAS. The high internal consistency of the scale revealed that the 21 bidimensional items (10 negative, 11 positive) turned out to be an internally consistent measure of RAS construct. Thus, the responses were highly reliable, stable, and reflected true measurement of retirement adjustment. The Kaiser-MeyerOlkin (KMO) sampling adequacy measure yielded 0.07, considered to be high enough to show the sample data sufficiency undergo factor analysis, while the Bartlett's Test of Sphericity yielded $p<0.001$ to show that the principal Component analysis was sensible, and the Cronbach value of 0.782 confirmed the item's reliability. The Screen plot result similarly confirmed it, as the Eigen value was higher than 1.00 among the first six factors. With these psychometric properties, RAS was thus considered valid and reliable for measuring retirement adjustment among secondary school teacher-retirees in Nigeria.

Effectiveness, a noun, is derived from effective, an adjective. According to [12], in the Longman Dictionary of Contemporary English, the first meaning ascribed to "effective" is "successful, and working in the way that was intended". Therefore, the effectiveness of a scale is the exploration of how successfully the scale is able to measure what it was designed to measure.

\section{Objectives of the Study}

The study explored the practical workability of measuring retirement adjustment intended for Retirement Adjustment Scale (RAS) among teachers who retired from primary and secondary schools in Ekiti and Osun States of the Southwestern Nigeria. It also investigated the effectiveness or otherwise of RAS among the respondents based on their demographics such as gender, educational attainment, and institution of service before transition into retirement.

\section{Methodology}

The research design adopted for the study was survey. The population comprised all teachers who retired from the primary and secondary schools in Ekiti and Osun States of Southwestern Nigeria. The sample size $(n=650)$ was selected through a multi-stage sampling. In the first stage, purposive sampling was used to select two states, namely Ekiti and Osun from among the six States (Ekiti, Lagos, Ogun, Ondo, Osun, and Oyo) making the Southwestern Nigeria. In the second stage, purposive sampling technique was used to select only retirees from both primary and secondary schools from Ekiti and Osun States. Snowballing was used in the third stage in two respects, namely meeting retirees known to the researchers and finding out about residences of other retirees from them, and consulting retirees in their meeting venues to ask for direction on reaching other retirees in their meeting venues at their meeting days. Fourthly, intact sampling was used to select the entire retirees in their meeting venues as they were available and ready to participate in the study. Data collection processes in the two states were in two stages, namely data collected by the researchers themselves, and those collected by research assistants employed and trained by the researchers. In the first stage, the researchers collected data in the meeting venues of the retirees on their meeting days. In doing this, the lead-researcher introduced the researchers and the purpose of the study. The leadresearcher intimated the intended participants that information they shared would be confidential, adding that they were free to participate or decline to participate in the research. With the express permission of the retirees' executives, copies of the questionnaire were distributed to the meeting attendees. Some retirees declined to participate on the excuse that they were not with their reading glasses, but when it was explained to them that they could go home with their copies of questionnaire and return them after filling out, they accepted to participate; some others however still declined to participate. Many of the retirees who received the copies exhorted the researchers to wait for the collection after their meeting, which the researchers did. For those who consented to take theirs home and return them to the meeting venue for collection by the researchers after filling-in, the leadresearcher introduced research assistants in each venue who would follow-up on the retirees to collect the copies from them in their subsequent meetings. This method was adopted for use in each of the collection venues both in Ekiti and Osun States covered in the study. In all, 650 copies of questionnaire were administered, 594 copies 
were returned, while 18 copies were invalid (leaving out 576 copies that were analyzed which represented $91 \%$ return rate). In all, it took ten months (February to November 2020) to collect the data. It appeared to have taken that long because of the COVID-19 pandemic lockdown in Nigeria between ending of March to late July 2020. Data analysis were done using frequency counts, standard deviation, and chi-square.

\section{Research Question}

What is the level of effectiveness of RAS in measuring the retirement adjustment of retirees in Ekiti and Osun States?

\section{Research Hypotheses}

1. There will be no significant difference in the effectiveness of RAS in measuring the retirement adjustment of teacher-retirees in Ekiti and Osun States on the basis of sex.

2. There will be no significant difference in the effectiveness of RAS in measuring the retirement adjustment of teacher-retirees in Ekiti and Osun States on the basis of educational attainment.

3. There will be no significant difference in the effectiveness of RAS in measuring the retirement adjustment of teacher-retirees in Ekiti and Osun States on the basis of institution of service.

Table 1. Demographic Analysis of the RAS.

\begin{tabular}{|c|c|c|c|}
\hline & & Frequency $(\mathbf{F})$ & Percent (\%) \\
\hline \multicolumn{4}{|l|}{ Retiree Sex } \\
\hline & Male & 328 & 56.9 \\
\hline & Female & 248 & 43.1 \\
\hline & Total & 576 & 100.0 \\
\hline \multicolumn{4}{|c|}{ Type of Family } \\
\hline & Monogamy & 457 & 79.3 \\
\hline & Polygamy & 119 & 20.7 \\
\hline & Total & 576 & 100.0 \\
\hline \multicolumn{4}{|c|}{ Educational Attainment } \\
\hline & Teacher Grade II/ACE & 46 & 8.0 \\
\hline & NCE & 297 & 51.6 \\
\hline & First Degree & 207 & 35.9 \\
\hline & Masters/PhD & 26 & 4.5 \\
\hline & Total & 576 & 100.0 \\
\hline \multicolumn{4}{|c|}{ Institution of Service before Retirement } \\
\hline & Primary School & 271 & 47.0 \\
\hline & Secondary school & 305 & 53.0 \\
\hline & Total & 576 & 100.0 \\
\hline
\end{tabular}

Table 1 revealed that out of the 576 participants voluntarily participated in this study, $56.9 \%$ were male and $43.1 \%$ were female. Also, for the type of family, $79.3 \%$ of the participants were from monogamous home while $20.7 \%$ were from polygamous home. The higher education of the retired teachers accounted for $8 \%, 51.6 \%, 35.9 \%$, and $4.5 \%$ with Teacher Grade II/ACE, NCE, First Degree and Masters/PhD respectively. For the institution of service before retirement, $47 \%$ of the participants served in primary schools while $53 \%$ served in secondary schools prior to their retirement.

\section{Results}

What is the level of effectiveness of RAS in measuring the retirement adjustment of retirees in Ekiti and Osun States?

In answering this research question, the RAS were scored $0,1,2,3$, and 4 for positive items and negative items were scored in reverse order. The total score for each retiree was computed with a minimum and maximum values of 35 and 80 respectively, with a mean and standard deviation $(\bar{X}=$ 53.11 and $\mathrm{SD}=7.25)$. A score that was less than the mean minus one standard deviation was categorized as low effectiveness $(35-48.85)$, while scores between the range of the mean minus one standard deviation and the mean plus one standard were categorized as moderate effectiveness $(48.86-60.36)$ and scores above the mean plus one standard deviation were categorized as high effectiveness (60.37 80). Also, the frequency count and percentage for each category were obtained and cross tabulated with the demographic characteristics to ascertain the level of effectiveness of the RAS using the chi square statistic and the result was as presented in Table 2 .

Table 2 shows the level of effectiveness of the RAS in measuring the retirement adjustment of the retirees in Osun and Ekiti States. It was noticed that there was no statistically significant effect of RAS on retirees' sex $\left(\chi^{2}=1.376, \mathrm{p}>\right.$ $0.05)$ and type of family $\left(\chi^{2}=2.046, p>0.05\right)$, whereas there was a significant effect of RAS on retirees' educational attainment $\left(\chi^{2}=22.823, \mathrm{p}<0.05\right)$ and institution of service before retirement $\left(\chi^{2}=37.974, \mathrm{p}<0.05\right)$.

Hypothesis One: There will be no significant difference in the effectiveness of RAS in measuring the retirement adjustment of teacher-retirees in Ekiti and Osun States on the basis of sex. 
Table 2. Level of Effectiveness of RAS.

\begin{tabular}{|c|c|c|c|c|c|c|c|}
\hline & & Low Effectiveness & Moderate Effectiveness & High Effectiveness & df & $x 2$ & Sig \\
\hline \multirow{3}{*}{ Retiree Sex } & Male & $67(20.5 \%)$ & $220(67.3 \%)$ & $40(12.2 \%)$ & \multirow{3}{*}{2} & \multirow{3}{*}{1.376} & \multirow{3}{*}{$>0.05$} \\
\hline & Female & $61(24.6 \%)$ & $158(63.7 \%)$ & $29(11.7 \%)$ & & & \\
\hline & Total & $128(22.3 \%)$ & $378(65.7 \%)$ & $69(12.0 \%)$ & & & \\
\hline \multirow{3}{*}{ Type of Family } & Monogamy & $106(23.3 \%)$ & $299(65.4 \%)$ & $52(11.4 \%)$ & \multirow{3}{*}{2} & \multirow{4}{*}{2.046} & \multirow{3}{*}{$>0.05$} \\
\hline & Polygamy & $22(18.5 \%)$ & $79(66.4 \%)$ & $18(15.1 \%)$ & & & \\
\hline & Total & $128(22.2 \%)$ & $378(65.6 \%)$ & $70(12.2 \%)$ & & & \\
\hline \multirow{5}{*}{$\begin{array}{l}\text { Educational } \\
\text { Attainment }\end{array}$} & Teacher Grade II/ACE & $14(30.4 \%)$ & $23(50.0 \%)$ & $9(19.6 \%)$ & \multirow{5}{*}{6} & & \multirow{5}{*}{$<0.05$} \\
\hline & NCE & $66(23.0 \%)$ & $203(70.7 \%)$ & $18(6.3 \%)$ & & \multirow{4}{*}{22.823} & \\
\hline & First Degree & $39(18.8 \%)$ & $131(63.3 \%)$ & $37(17.9 \%)$ & & & \\
\hline & Masters/Ph.D. & $8(30.8 \%)$ & $15(57.7 \%)$ & $3(11.5 \%)$ & & & \\
\hline & Total & $127(22.4 \%)$ & $372(65 \% .7)$ & $67(11.8 \%)$ & & & \\
\hline \multirow{3}{*}{$\begin{array}{l}\text { Institution of Service } \\
\text { before retirement }\end{array}$} & Primary School & $70(25.8 \%)$ & $192(70.8 \%)$ & $9(3.3 \%)$ & \multirow{3}{*}{2} & \multirow{3}{*}{37.974} & \multirow{3}{*}{$<0.05$} \\
\hline & Secondary school & $56(19.0 \%)$ & $186(61.0 \%)$ & $61(20.0 \%)$ & & & \\
\hline & Total & $128(22.2 \%)$ & $378(65.6 \%)$ & $70(12.2 \%)$ & & & \\
\hline
\end{tabular}

Table 3. Descriptive Statistics.

\begin{tabular}{llllll}
\hline Descriptive Statistics & & & & \\
\hline & N & Minimum & Maximum & Mean & Std. Deviation \\
\hline Retiree Sex & 576 & 1 & 2 & 1.43 & .496 \\
'Type of Family & 576 & 1 & 2 & 1.21 & .405 \\
Higher Education Qualification & 576 & 1 & 4 & 2.37 & .696 \\
Institution of Service before retirement & 576 & 1 & 2 & 1.53 & .500 \\
Valid N (listwise) & 576 & & & & \\
\hline
\end{tabular}

Table 4. Retirement Adjustment of Retired Teachers on the Basis of Sex.

\begin{tabular}{lllllll}
\hline Sex & N & Mean & Std. Deviation & df & t & Sig. \\
\hline Male & 328 & 53.53 & 7.202 & \multirow{2}{*}{574} & \multirow{2}{*}{1.593} & \multirow{2}{*}{0.564} \\
Female & 248 & 52.56 & 7.292 & 29 & \\
\hline
\end{tabular}

Not significant, $\mathrm{p}>0.05$.

Table 4 reveals that there was no significant difference in the effectiveness of RAS in measuring the retirement adjustment of the retired teachers on the basis of sex $(\mathrm{t}=$ $1.593, \mathrm{p}>0.05)$. It was also noticed from Table 2 that there was no statistically significant effect of RAS on retirees' sex $\left(\chi^{2}=1.376, p>0.05\right)$. The implication of this is that the RAS measured the retirement adjustment of male and female retired teachers without any significant difference.

Hypothesis Two: There will be no significant difference in the effectiveness of RAS in measuring the retirement adjustment of teacher-retirees in Ekiti and Osun States on the basis of educational attainment.

The RAS was subjected to critical statistical analysis of chisquare. The effectiveness of RAS was tested against the higher education qualification of the retired teachers. The retirement adjustment of the retired teachers was categorized into low, moderate, and high retirement adjustment. The minimum and maximum scores of the retired teachers were 35 and 80 respectively with a mean and standard deviation of 53.10 and 7.259 respectively. The mean score minus standard deviation and the mean score plus standard deviation was categorized as the moderate retirement adjustment $(45.84-60.34)$, while the range from minimum score to the 0.01 minus the lower limit of moderate retirement adjustment was grouped into low retirement adjustment $(35-45.83)$. For the high category of retirement adjustment, 0.01 plus the upper limit of the moderate retirement adjustment and the maximum score was utilized $(60.35$ - 80). Likewise, the frequency count and percentage of each groups of retirement adjustment were obtained and cross-tabulated with the higher education qualification of the retired teachers to verify whether there would be significant difference in the effectiveness of RAS in measuring the retirement adjustment of retired teachers on the basis of educational attainment using chi-square $\left(\chi^{2}\right)$ statistic.

Table 5. Retirement Adjustment of Retired Teachers and Higher Educational Qualification.

\begin{tabular}{|c|c|c|c|c|c|c|c|}
\hline \multirow{2}{*}{ Educational Attainment } & \multicolumn{3}{|c|}{ Level of Retirement Adjustment } & \multirow{2}{*}{$\chi^{2}$} & \multirow{2}{*}{ df } & \multirow[b]{2}{*}{ Sig } & \multirow{2}{*}{$\mathbf{P}$} \\
\hline & Low & Moderate & High & & & & \\
\hline Grade II/ACE & $12(2.1 \%)$ & $25(4.3 \%)$ & $9(1.6 \%)$ & \multirow{4}{*}{41.686} & \multirow{4}{*}{6} & \multirow{4}{*}{.000} & \multirow{4}{*}{$<.05$} \\
\hline NCE & $24(4.2 \%)$ & $252(43.8 \%)$ & $21(3.6 \%)$ & & & & \\
\hline First Degree & $31(5.4 \%)$ & 139 (24.1\%) & $37(6.4 \%)$ & & & & \\
\hline Masters/PhD & $8(1.4 \%)$ & $15(2.6 \%)$ & $3(0.5 \%)$ & & & & \\
\hline
\end{tabular}

Table 5 reveals a significant difference in the effectiveness 
teachers in Ekiti and Osun States on the basis of their educational qualification $\left(\chi^{2}=41.686 ; \mathrm{p}<0.05\right)$. This implies that higher education made significant difference in retirement adjustment of retired teachers.
Hypothesis Three: There will be no significant difference in the effectiveness of RAS in measuring the retirement adjustment of teacher-retirees on the basis of institution of service before retirement.

Table 6. Retirement Adjustment of Retired Teachers and Institution of Service Before Retirement.

\begin{tabular}{|c|c|c|c|c|c|c|}
\hline Institution of Service before Retirement & $\mathbf{N}$ & Mean & Std. Deviation & Df & $\mathbf{t}$ & Sig. \\
\hline Primary School & 271 & 51.43 & 5.896 & \multirow{2}{*}{574} & \multirow{2}{*}{-5.335} & \multirow{2}{*}{0.00} \\
\hline Secondary school & 305 & 54.59 & 8.006 & & & \\
\hline
\end{tabular}

Significant, $\mathrm{p}<0.05$.

Table 6 displays that secondary school retired teachers had a higher mean score $\left(\mathrm{X}^{-}=54.59\right)$ than their primary school $\left(X^{-}=51.43\right)$ counterparts $(t=-5.335, p<0.05)$. The implication of this is that there is a significant difference in the effectiveness of RAS among primary and secondary school retirees in measuring their retirement adjustment with the effectiveness of RAS higher for secondary school teacher-retirees than primary school teachers.

\section{Discussion of Findings}

The only research question proved the level of effectiveness of RAS in measuring the retirement adjustment of retirees in Ekiti and Osun States. The finding revealed that the level of effectiveness of RAS in measuring the retirement adjustment of retiree was moderately high. The finding that revealed that RAS had a moderately high effectiveness is similar to the findings of [13] who established a moderate level each of retirement adjustment, social support, and psychological wellbeing among teacher-retirees in Osun State. The similarities established in the findings of the two studies could be ascribed to the fact that retirees are affected by a number of constructs in almost exactly the same way. Hypothesis one stated that there will be no significant difference in the effectiveness of RAS in measuring the retirement adjustment of retired teachers in Ekiti and Osun States on the basis of sex. The findings affirmed the hypothesis. The findings showed that RAS was practically effective in measuring the retirement adjustment of the retirees from the two States without discrimination arising from their sex. This could be as a result of the political tone of the two States when salaries were delayed and some retirees were subjected to half salary, thereby workers and retirees were forced to adjust to the situations they found themselves, and the socio-economic situation in the two States tend to bring in the revealed adjustment. This negates the findings obtained by [14] that males and females were different in their spending and savings and females had negative attitude toward retirement than males do, and that retirement was more disruptive and more likely to be linked with gender, loneliness, and depression for females than for males.

The second hypothesis stipulated that there will be no significant difference in the effectiveness of RAS in measuring the retirement adjustment of retired teachers in Ekiti and Osun States on the basis of their educational attainment. The finding showed that a significant difference existed in the effectiveness of RAS in measuring the adjustment of the retired teachers. The post hoc findings also confirmed that higher education made a significant difference in retirement adjustment of retired teachers. Education being the cornerstone for better adjustment helps an individual to view stressful life events without overestimating or over valuing the situation. Increased level of education makes an individual more knowledgeable and more mature in their behavior and makes it easy for them to accept facts. Education makes people acquire a range of control over events because they are accessible to information that enables then form a central opinion of the prevailing events. Therefore, the resulted significant difference could not be strange. The finding negated the findings of [15] who could not establish any difference in the perception of university academics on factors influencing retirement preparedness of workers on the basis of academic qualification. The difference between the two findings could be that while the academic used in [15] were serving workers, the respondents in the present study were retirees. Thus, the disparity between being a worker and being a retiree could make a different judgement on retirement phenomenon among the two groups.

The third hypothesis stated that there will be no significant difference in the effectiveness of RAS in measuring the retirement adjustment of the retired teachers in Ekiti and Osun States on the basis of institution of service before retirement. The findings negated the hypothesis. The result therefore showed how the retiree's adjustment was influenced by where they worked while in service (be it primary or secondary school). The direction of the significant difference in RAS effectiveness was higher for the secondary school teacher-retirees above their primary school counterparts. What is likely responsible for this could be that in terms of payment of retirement benefits to primary and secondary school teachers, the secondary school teacherretirees received relatively better consideration. During the COVID-19 lockdown for instance, [16] found that while primary school teacher-retirees experienced percentage cutdown in the payment of their monthly pension by Ondo State Government, the secondary school teacher-retirees received their full monthly pension from the same government; such discrepancies could result into differences in retirement adjustment between the primary and secondary school teacher-retirees. 


\section{Conclusion}

It could be concluded from the findings of the study that RAS is effective in measuring the retirement adjustment of teacher-retirees from both primary and secondary schools on the most important variables of sex while variation may exist in the matter of their educational attainment and institution of service prior to retirement.

\section{Recommendations}

The Retirement Adjustment Scale (RAS) is a highly effective scale that could measure the retirement adjustment of teachers at the primary and secondary levels of education in Nigeria. It is recommended for use by retirement counsellors and retirement researchers in exploring the retirement adjustment of teachers. For diagnostic purpose, after the administration of RAS, retirement counsellors should be more concerned about the results of each of their clients on RAS with emphasis on each of the items on the scale to determine the requisite retirement guidance and counselling for the respective clients. Men and women that have developed strong occupational attachment to work should not view the transition problematic causing frustration in the domestic sphere but socialization and friendship relations between retirees and their families, friends and significant persons should be encouraged. This would provide them with social and emotional support that will act as a significant antidote against psychological stress.

\section{References}

[1] Cornman, J., \& Kingston, E. (1996). Trends, issues, perspectives and values for the aging of the baby boom cohorts. The Gerontologist, 36 (1), 15-26.

[2] Atchley, R. C. (1976) The sociology of retirement, New York Schenkman Publishing Company.

[3] Adeyemo, E. O., \& Olatomide, O. O. (2017). Validation of Retirement Adjustment Scale for retired teachers of secondary schools in Osun State, Nigeria. International Journal of Education and Research, 5 (8), 209-220.

[4] Akinade, E. A. (1993). Towards satisfactory retirement: A sociopsychological approach. Lagos: Kola Okanlawon Services Ltd.
[5] Nuttman-Shwartz, O. (2004). Like a high wave: Adjustment to retirement. The Gerontologist, 44, 229-236.

[6] Lindwall, M., Berg, A. I., Bjalkebring, P., Buratti, S., Hansson, I., Hassing, L., Henning, G., Kivi, M., Konig, S., Thorvaldsson, V., \& Johansson, B. (2017). Psychological health in the retirement transition: Rationale and first findings in the Health, Ageing and Retirement Transitions in Sweden (HEARTS) study. Frontiers in Psychology 8: 1634. doi: 10.3389/fpsyg.2017.01634. Accessed from www.frontiersin.org.

[7] Ejeh, V. J., Igbokwe, C. C., \& Onoja, H. N. (2020). Determination of depression, anxiety and stress among retirees in Kogi State and preventive strategies. International Journal of Education, Learning and Development, 8 (3), 62-74.

[8] Sokoh, G. C. (2017). Age falsification and its impact on continuity and service delivery in Delta State civil service. Journal of Humanities and Social Science, 22 (9), 52-63.

[9] Garba, A., \& Mamman J., (2004). Retirement challenges and sustainable development in Nigeria. European Journal of Business and Management, 6, 94-98.

[10] Olatomide, O. O. (2010) Challenges facing civil and public retirees in Ekiti and Oyo States: Implication for national development and increased life expectancy. Nigerian Journal of Educational Research and Evaluation, 9 (2), 85-94.

[11] Olatomide, O. O. (2014). Education and human development issues in Nigeria: The points of disconnectedness of Nigerian retirees. The African Symposium: An Online Journal of The African Educational Research Network, 14 (1 \& 2), 158-165.

[12] Mayor, M. et al., (2009). Longman dictionary of contemporary English (5 ${ }^{\text {th }}$ ed.). England: Pearson Education Limited.

[13] Olatomide, O. O. (2020). What is the relationship among preretirement guidance, social support and psychological wellbeing on retirement adjustment of teacher-retirees in Osun State? Inkanyiso, The Journal of Humanities and Social Sciences, 12 (1), 99-109.

[14] Fadila, D. S., \& Alam, R. R. (2016). Factors affecting adjustment to retirement among retirees' elderly persons. Journal of Nursing Education and Practice, 6 (8), 112-122.

[15] Olatomide, O. O., \& Ajeigbe T. O. (2020) Retirement preparedness of workers as perceived by university lecturers in Nigeria. Journal of Education, Psychology and Research, 1 (2), 50-65.

[16] Olatomide, O. O. (2020). Psycho-economic adjustment strategies of retirees during the COVID-19 pandemic in Ondo State, Nigeria. Journal of Counselling and School Psychology, $3(1), 53-62$. 